\title{
Virome in adult Aedes albopictus captured during different seasons in Guangzhou City, China
}

\author{
Wenqiao He ${ }^{\dagger}$, Yanxia Chen ${ }^{\dagger}$, Xiru Zhang, Mingji Peng, Da Xu, Huan He, Yuhan Gao, Junlin Chen, Jiarui Zhang,
} Zhiyu Li and Qing Chen ${ }^{*}$

\begin{abstract}
Background: The mosquito Aedes albopictus is an important vector for many pathogens. Understanding the virome in Ae. albopictus is critical for assessing the risk of disease transmission, implementation of vector control measures, and health system strengthening.

Methods: In this study, viral metagenomic and PCR methods were used to reveal the virome in adult Ae. albopictus captured in different areas and during different seasons in Guangzhou, China.

Results: The viral composition of adult Ae. albopictus varied mainly between seasons. Over 50 viral families were found, which were specific to vertebrates, invertebrates, plants, fungi, bacteria, and protozoa. In rural areas, Siphoviridae (6.5\%) was the most common viral family harbored by mosquitoes captured during winter and spring, while Luteoviridae (1.1\%) was the most common viral family harbored by mosquitoes captured during summer and autumn. Myoviridae (7.0\% and 1.3\%) was the most common viral family in mosquitoes captured in urban areas during all seasons. Hepatitis B virus (HBV) was detected by PCR in a female mosquito pool. The first near full-length HBV genome from Ae. albopictus was amplified, which showed a high level of similarity with human HBV genotype B sequences. Human parechovirus ( $\mathrm{HPeV}$ ) was detected in male and female mosquito pools, and the sequences were clustered with HPeV 1 and 3 sequences.

Conclusions: Large numbers of viral species were found in adult Ae. albopictus, including viruses from vertebrates, insects, and plants. The viral composition in Ae. albopictus mainly varied between seasons. Herein, we are the first to report the detection of HPeV and HBV in mosquitoes. This study not only provides valuable information for the control and prevention of mosquito-borne diseases, but it also demonstrates the feasibility of xenosurveillance.
\end{abstract}

Keywords: Aedes albopictus, Viral metagenomics, Season, Guangzhou

\section{Background}

Vector-borne infectious diseases affect over one billion people every year, leading to more than a million deaths globally [1]. Aedes albopictus (Ae. albopictus), a diurnal

\footnotetext{
*Correspondence: 18002270308@163.com

'Wenqiao He and Yanxia Chen contributed equally to this work Department of Epidemiology, School of Public Health, Guangdong Provincial Key Laboratory of Tropical Disease Research, Southern Medical University, 1838 Guangzhou North Road, Guangzhou 510515, China mosquito, is considered to be one of the most invasive animal species in the world. It was originally indigenous to the tropical and subtropical regions of southern Asia [2]. However, with the movement of humans and climate change, it has spread to many places in the world [3]. Except for Antarctica, Ae. albopictus is now found on all continents [4].

Ae. albopictus is a competent vector of at least 22 arboviruses that can cause human infections, including Zika original author(s) and the source, provide a link to the Creative Commons licence, and indicate if changes were made. The images or other third party material in this article are included in the article's Creative Commons licence, unless indicated otherwise in a credit line to the material. If material is not included in the article's Creative Commons licence and your intended use is not permitted by statutory regulation or exceeds the permitted use, you will need to obtain permission directly from the copyright holder. To view a copy of this licence, visit http://creativecommons.org/licenses/by/4.0/. The Creative Commons Public Domain Dedication waiver (http://creativeco mmons.org/publicdomain/zero/1.0/) applies to the data made available in this article, unless otherwise stated in a credit line to the data. 
virus (ZIKV), dengue virus (DENV), chikungunya virus (CHIKV), and yellow fever virus (YFV) [5]. Outbreaks caused by arboviruses have been reported, such as dengue fever in Thailand, Vietnam, and China, and chikungunya in France, Tanzania, Africa, and the Americas [2, 6-13]. ZIKV infections have also been reported in many countries, including Brazil, Nicaragua, and America [14-16].

China is a country located in East Asia. Most of the regions in this country are in the temperate zone, while some southern regions are located in the subtropical and tropical zones [17]. Ae. albopictus is found in nearly one third of the regions in China: south to Hainan Island, north to Shenyang and Dalian, west to Jingshui and Longnan, southwest to the Tibet Autonomous Region, and most regions to the east [18-20].

Some mosquito-borne diseases are prevalent in China. Since the first outbreak of dengue fever in 1978, this disease has been a threat for over 40 years in China, especially in southern and southeastern China [21]. Ae. albopictus was the sole vector responsible for some dengue fever outbreaks [22-26]. Outbreaks of chikungunya related to Ae. albopictus have also been reported in China $[23,27,28]$. Major public health concerns have been raised in China due to these frequent outbreaks [29].

Guangzhou $\left(23^{\circ} 08^{\prime} \mathrm{N}, 113^{\circ} 16^{\prime} \mathrm{E}\right)$, the capital city of Guangdong Province, is located in southern China, and it is the fourth most populous city in the entire country [30]. The average annual temperature in Guangzhou is $22-23{ }^{\circ} \mathrm{C}$, and the average rainfall is $1983 \mathrm{~mm}[31,32]$. Ae. albopictus is active in Guangzhou nearly all year round [33]. In 2014, there were 38,036 dengue cases reported in Guangzhou, accounting for $80.8 \%$ of all cases in the largest dengue outbreak in mainland China since 1990 [32, 34]. In addition, some sporadic cases of imported CHIKV infection were also reported in Guangzhou [35]. There is a great need for mosquito surveillance and control in Guangzhou.

Next-generation sequencing enables efficient detection of known and unknown viruses [36-38]. Viruses in Aedes, Culex, Anopheles, and Armigeres mosquitoes have been revealed using these methods. Some known viruses have been detected, such as DENV, ZIKV, and West Nile virus [39-43]. Novel viruses such as the Cuacua virus in Mansonia mosquitoes and the novel orbivirus in Culex fatigans mosquitoes have also been detected [37, 44]. Understanding the viral composition in mosquitoes is important for the prevention and control of emerging and reemerging mosquito-borne diseases. However, few studies have used next-generation sequencing methods to investigate the virome in Ae. albopictus [45, 46].

In this study, viral metagenomic and polymerase chain reaction (PCR) methods were used to reveal the viral composition in adult Ae. albopictus captured in different areas and during different seasons in Guangzhou City, China.

\section{Methods \\ Sample collection}

Between September 2017 and August 2018, adult Ae. albopictus specimens were collected three times per month in rural and urban areas in Guangzhou. The rural areas included Xiongwei and Nanfang villages in the Baiyun district, and the urban areas consisted of the Keyuan community in the Yuexiu district and the Taozhuang community in the Tianhe district. The captured mosquitoes were morphologically identified to determine their species and sex [37]. A total of 3346 adult Ae. albopictus were trapped (Additional file 1: Tables S1 and S2). All samples were stored at $-80^{\circ} \mathrm{C}$ in tubes containing RNAlater prior to processing.

Laboratory viral metagenomic experiments

According to the collection sites and seasons, mosquitoes were randomly selected and pooled into four samples for viral metagenomic analysis (Additional file 1: Table S1). Pooled samples were homogenized in liquid nitrogen and then suspended in phosphate-buffered saline (PBS) $[47,48]$. The supernatant was filtered through a $0.22-\mathrm{mm}$ filter, and the filtered samples were then concentrated using centrifugal ultrafiltration tubes. To remove nonparticle-protected nucleic acids, samples were incubated at $37{ }^{\circ} \mathrm{C}$ for $2 \mathrm{~h}$ with a mixture of DNases and RNase (New England Biolabs, USA). The total DNA and RNA of the pooled specimens was extracted using the MiniBEST Viral RNA/DNA Extraction Kit (TaKaRa, Japan). Reverse transcription was performed using the Transcriptor First Strand cDNA Synthesis Kit (Roche, Switzerland), and the primer used was reported in a previous study [49]. Random PCR was performed using the primer described in a previous study, and the purified PCR products were then obtained using the QIAquick Gel Extraction Kit (Qiagen, Germany) [49]. Libraries were constructed with the TruSeq $^{\text {TM }}$ DNA Sample Prep Kit (Illumina). The libraries were sequenced using the Illumina HiSeq platform at Shanghai Majorbio Bio-Pharm Technology Co., Ltd. (Shanghai, China) with 300-bp paired-end reads.

\section{Bioinformatics analysis of viral metagenomics}

The quality score cut-off value was 20 , and sequences with ambiguous bases (more than $10 \mathrm{bp} \mathrm{N}$ ) and short length reads (less than $50 \mathrm{bp}$ ) were removed using the Sickle program (https://github.com/najoshi/sickle). To remove host-related sequences, quality reads were aligned with the host genome via BWA [50]. Reads with a high degree of similarity to the hosts' genome were removed in further analyses. The taxonomic assignments 
were based on the National Center for Biotechnology Information (NCBI) nucleotide (NT) and non-redundant protein sequence (NR) databases, and the functional categories were based on the MetaGene system. In addition, the short reads were assembled using the IDBA-UD algorithm based on the de Bruijn graph approach [51]. The assembled contigs were analyzed based on the NCBI NR database. Phylogenetic analyses were performed using the MEGA 6.0 program with the maximum likelihood method.

\section{Extraction of nucleic acid and detection of viruses using PCR}

Mosquitoes with the same sampling season, location, and sex were pooled into 196 samples (3-18 mosquitoes per sample) to perform PCR confirmatory tests (Additional file 1: Table S2). Using a MiniBEST Viral RNA/DNA Extraction Kit (TaKaRa, Japan), total RNA and DNA from these mosquito pools was extracted. Three arboviruses (ZIKV, DENV, and CHIKV) and some vertebrate viruses with high relative abundance in viral metagenomics were detected using PCR, including human parechovirus ( $\mathrm{HPeV})$, torque teno virus (TTV), coronavirus, herpesvirus, and hepatitis B virus (HBV) [52-58].

\section{Results}

\section{Sample collection}

A total of 990 mosquitoes were randomly selected for viral metagenomic analysis, and others (2356 Ae. albopictus) were pooled and applied to survey the prevalence and genomic diversity of the viruses using PCR (Additional file 1: Tables S1 and S2).

\section{Data overview of viral metagenomics}

An average of 45,012,644 raw reads, 27,464,028 clean reads, 47,002 contigs, and 22,280 open reading frames (ORFs) was obtained for each sample (NCBI SRA number: SRP304029) (Additional file 1: Table S3). The majority of the sequences (over 80\%) detected in our study were unidentifiable based on sequence similarity. Larger numbers of viral species were detected in mosquitoes captured during winter and spring as compared to mosquitoes captured during summer and autumn (Table 1). The viral composition in the mosquitoes mainly varied between seasons (Figs. 1 and 2).

The viruses detected in Ae. albopictus were specific to vertebrates, invertebrates, plants, fungi, bacteria, and protozoa (Fig. 3). Invertebrate viruses were detected with the highest relative abundance in all groups, especially in the mosquitoes that were captured in summer and autumn. Plant viruses and phage also had high relative abundance in all groups, followed by vertebrate viruses. The relative abundance of vertebrate viruses was lower
Table 1 Number of families, genera and species of viruses detected in mosquitoes according to season and area

\begin{tabular}{llll}
\hline $\begin{array}{l}\text { Mosquito } \\
\text { group }^{a}\end{array}$ & No. of families & No. of genera & No. of species \\
\hline SR & 40 & 65 & 245 \\
SU & 37 & 65 & 236 \\
WR & 42 & 74 & 254 \\
WU & 37 & 71 & 368 \\
\hline
\end{tabular}

${ }^{a}$ SR: mosquitoes captured in rural areas during summer and autumn; WR: mosquitoes captured in rural areas during winter and spring; SU: mosquitoes captured in urban areas during summer and autumn; WU: mosquitoes captured in urban areas during winter and spring

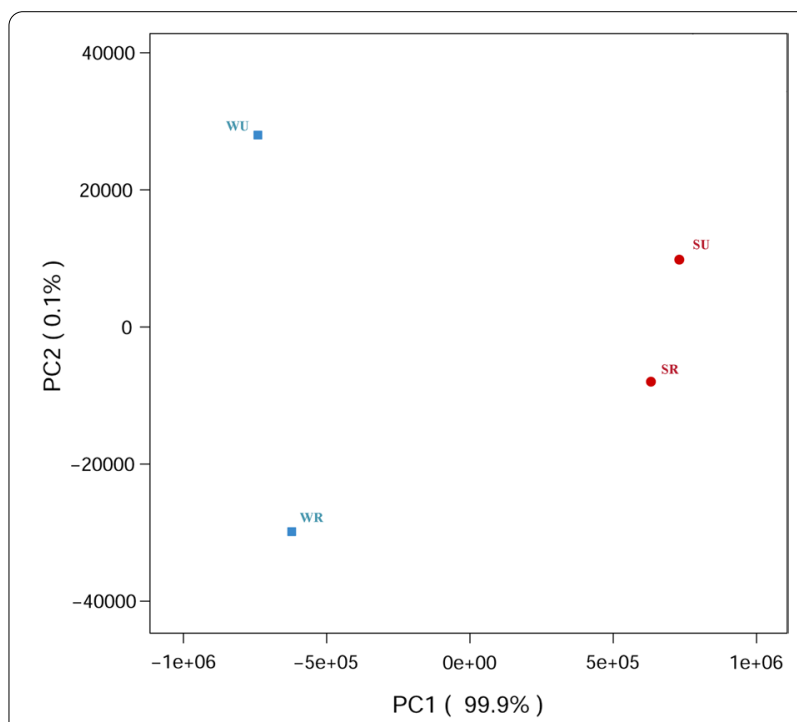

Fig. 1 Principal component analysis (PCA) plots between mosquitoes captured at different locations and during different seasons. The viral composition mainly varied between the seasons. SR: mosquitoes captured in rural areas during summer and autumn; WR: mosquitoes captured in rural areas during winter and spring; SU: mosquitoes captured in urban areas during summer and autumn; WU: mosquitoes captured in urban areas during winter and spring

in the mosquitoes captured in summer and autumn than that of the mosquitoes captured in winter and spring.

\section{Viral composition in Ae. albopictus}

In rural areas, Siphoviridae (6.5\%), Luteoviridae (4.3\%), and Coronaviridae (3.7\%) were the top three viral families harbored by the mosquitoes captured in winter and spring, while Luteoviridae (1.17\%), Siphoviridae (0.4\%), and Flaviviridae $(0.4 \%)$ were the most common viral families harbored by the mosquitoes captured in summer and autumn (Fig. 4). In urban areas, Myoviridae was the most common viral family in the mosquitoes captured during all seasons (winter and spring: 7.0\%; summer and autumn: $1.3 \%)$. Siphoviridae (3.8\%) and Podoviridae 


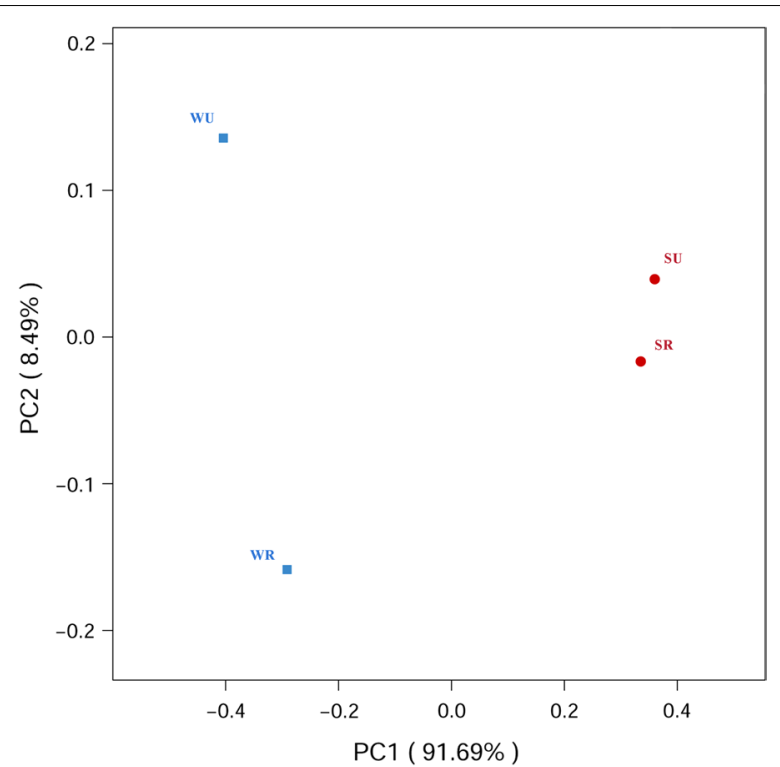

Fig. 2 Principal coordinates analysis (PCOA) plots between mosquitoes captured at different locations and during different seasons. The viral composition mainly varied between the seasons. SR: mosquitoes captured in rural areas during summer and autumn; WR: mosquitoes captured in rural areas during winter and spring; SU: mosquitoes captured in urban areas during summer and autumn; WU: mosquitoes captured in urban areas during winter and spring

(3.3\%) were the second and third most common viral families in mosquitoes that were captured during winter and spring, while Luteoviridae (0.3\%) and Siphoviridae $(0.3 \%)$ were common in mosquitoes captured in summer and autumn. Among the mosquitoes captured in winter and spring, Luteoviridae (4.3\%), Siphoviridae (6.5\%), Coronaviridae (3.7\%), Herpesviridae (1.0\%), Poxviridae (0.5\%), and Picornaviridae $(0.4 \%)$ were found with higher relative abundance in mosquitoes captured in rural areas, while Myoviridae (7.0\%), Podoviridae (3.3\%), and Mimiviridae (2.8\%) were more common in mosquitoes captured in urban areas. Higher relative abundance of Flaviviridae (0.4\%) and Polydnaviridae (0.2\%) was found in mosquitoes captured in rural areas during summer and autumn, while Myoviridae (1.3\%), Anelloviridae (0.2\%), Picornaviridae (0.1\%), and Podoviridae (0.1\%) were more common in mosquitoes captured in urban areas during the same seasons.

At the genus level, Sobemovirus and Polerovirus were the top two genera in all of the mosquitoes (Fig. 5). Alphacoronavirus ranked third in mosquitoes captured in rural areas during winter and spring, Flavivirus ranked third in mosquitoes captured in rural areas during summer and autumn, and Alphacoronavirus was the third most common viral genus in mosquitoes captured in urban areas during all seasons. In winter and spring, a higher relative abundance of Rhadinovirus (0.9\%) was detected in mosquitoes captured in rural areas as compared to mosquitoes captured in urban areas. However, in summer and autumn, Parechovirus (0.1\%) was more common in mosquitoes from urban areas, while a higher relative abundance of Sobemovirus (4.8\%), Polerovirus (1.1\%), Flavivirus (0.4\%), and Bracovirus (0.2\%) was found in mosquitoes captured in rural areas.

At the species level, Drosophila A virus, Sowbane mosaic virus, and Wheat yellow dwarf virus-GPV were the top three viral species in all of the mosquitoes (Fig. 6). In both urban and rural areas, Sowbane mosaic virus, Wheat yellow dwarf virus-GPV, Bat coronavirus Trinidad/1CO7BA/2007, Moumouvirus, Megavirus courdo7, Human immunodeficiency virus 1, and Hepatitis $B$ virus were found with higher relative abundance in mosquitoes captured during winter and spring, while Drosophila A virus and Mushroom bacilliform virus were more common in mosquitoes captured during summer and autumn. Mosquitoes trapped in winter and spring from rural areas exhibited higher relative abundance of Bat coronavirus Trinidad/1CO7BA/2007 (3.7\%) and Ateline herpesvirus 3 (0.9\%), while Hepatitis B virus (0.2\%) and Megavirus chiliensis (2.1\%) were more common in mosquitoes from urban areas. In summer and autumn, Torque teno virus (0.2\%) and Rhinovirus $C$ (0.1\%) exhibited higher relative abundance in mosquitoes from urban areas, while Aedes flavivirus (0.4\%), Small anellovirus (0.1\%), and Kamiti River virus (0.1\%) exhibited higher relative abundance in mosquitoes from rural areas.

\section{PCR confirmatory testing and phylogenetic analysis}

Although Ae. albopictus is one of the dominant vectors of ZIKV, DENV, and CHIKV, none of the Ae. albopictus in our study was positive for these viruses. Some vertebrate viruses in mosquitoes were detected using PCR, including $\mathrm{HPeV}$ and $\mathrm{HBV}$, while negative results were found in the detection of coronavirus, herpesvirus, and TTV (Table 2).

$\mathrm{HPeV}$ was detected in seven male and two female mosquito pools. Five of the screening sequences showed a high level of similarity with $\mathrm{HPeV} 3$ sequences, while four sequences were clustered with HPeV 1 (GenBank accession numbers: MW455086-MW455091 and MZ502310MZ502312) (Fig. 7).

HBV was only detected in one female mosquito pool from an urban area, and a near full-length HBV genome was amplified (TH5-11, GenBank accession number: MW411446). Both the screening sequence and the near full-length genome of HBV were clustered with human HBV genotype $B$ sequences (Fig. $8 \mathrm{a}$ and b). The nearly full-length genome exhibited a high level of similarity 

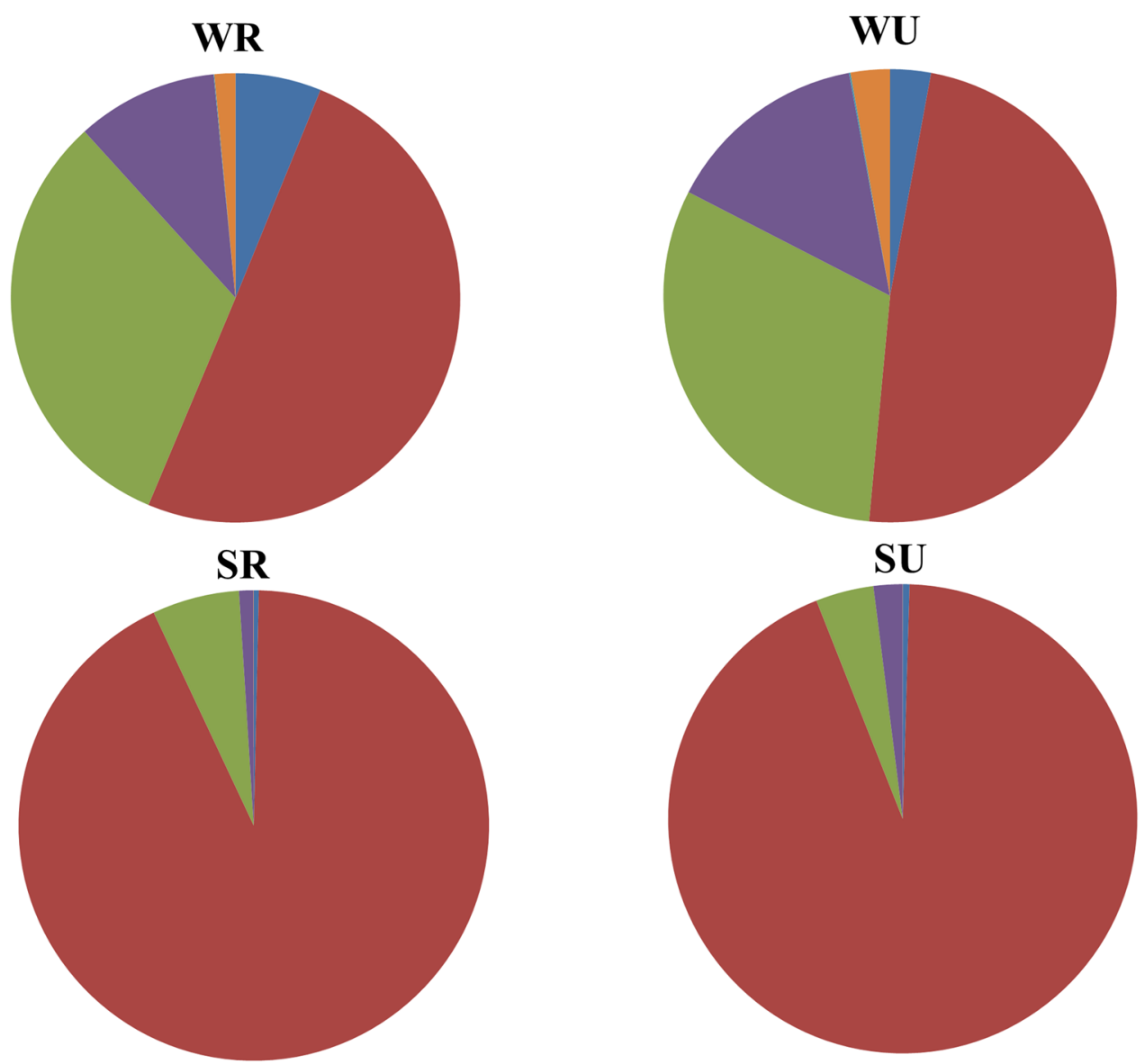

\section{$\square$ Vertebrate $\square$ Invertebrate $\square$ Plant $\square$ Phage $\square$ Mycovirus $\square$ Others}

Fig. 3 Viral sequences classified by host type. SR: mosquitoes captured in rural areas during summer and autumn; WR: mosquitoes captured in rural areas during winter and spring; SU: mosquitoes captured in urban areas during summer and autumn; WU: mosquitoes captured in urban areas during winter and spring

with the human HBV genotype B sequence (JX661478.1, 99.1\%) (Additional file 2: Table S4, Fig. 8b).

\section{Discussion}

Mosquito-borne diseases have greatly influenced human health. Aedes albopictus is an invasive animal species, and it is an important reservoir for many arboviruses, including DENV, ZIKV, and CHIKV [5]. Outbreaks of mosquito-borne infectious diseases related to Ae. albopictus have been reported. Because of the active movement of humans and climate change, Ae. albopictus is found in nearly one third of the regions in China [18]. Some mosquito-borne diseases associated with Ae. albopictus, such as dengue fever, are prevalent in China [59], and therefore, understanding the virome in Ae. albopictus is very important for the prevention and control of mosquitoborne diseases. Compared with traditional methods, viral metagenomics is more efficient for viral identification and discovery [60]. Many studies have used viral metagenomics to investigate the viruses in mosquitoes $[39,61,62]$. However, few studies have focused on Ae. albopictus.

In this study, viral metagenomics was performed to investigate the virome in adult Ae. albopictus captured in different areas and during different seasons in Guangzhou City, Guangdong Province, China. We also investigated the prevalence and genetic diversity of several arboviruses and vertebrate viruses in Ae. albopictus using PCR. To the best of our knowledge, this is the first study to reveal and compare the viral composition in adult Ae. albopictus captured in different areas and during different seasons in Guangzhou, China.

The viral composition in Ae. albopictus varied mainly between seasons, and the viral composition between 


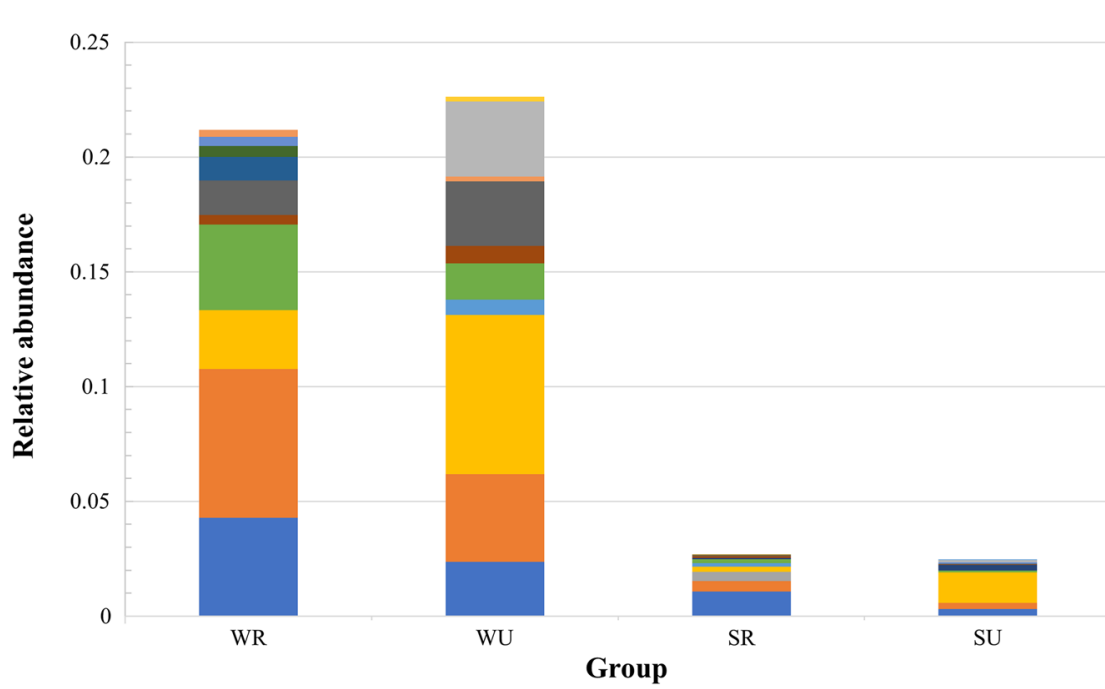

- Luteoviridae

- Siphoviridae

Flaviviridae

Myoviridae

- Polydnaviridae

Coronaviridae

- Anelloviridae

- Retroviridae

- Mimiviridae

- Tombusviridae

- Herpesviridae

- Poxviridae

- Picornaviridae

- Phycodnaviridae

Podoviridae

Hepadnaviridae

Baculoviridae

Fig. 4 The top ten viral families in the different groups of Ae. albopictus. SR: mosquitoes captured in rural areas during summer and autumn; WR: mosquitoes captured in rural areas during winter and spring; SU: mosquitoes captured in urban areas during summer and autumn; WU: mosquitoes captured in urban areas during winter and spring

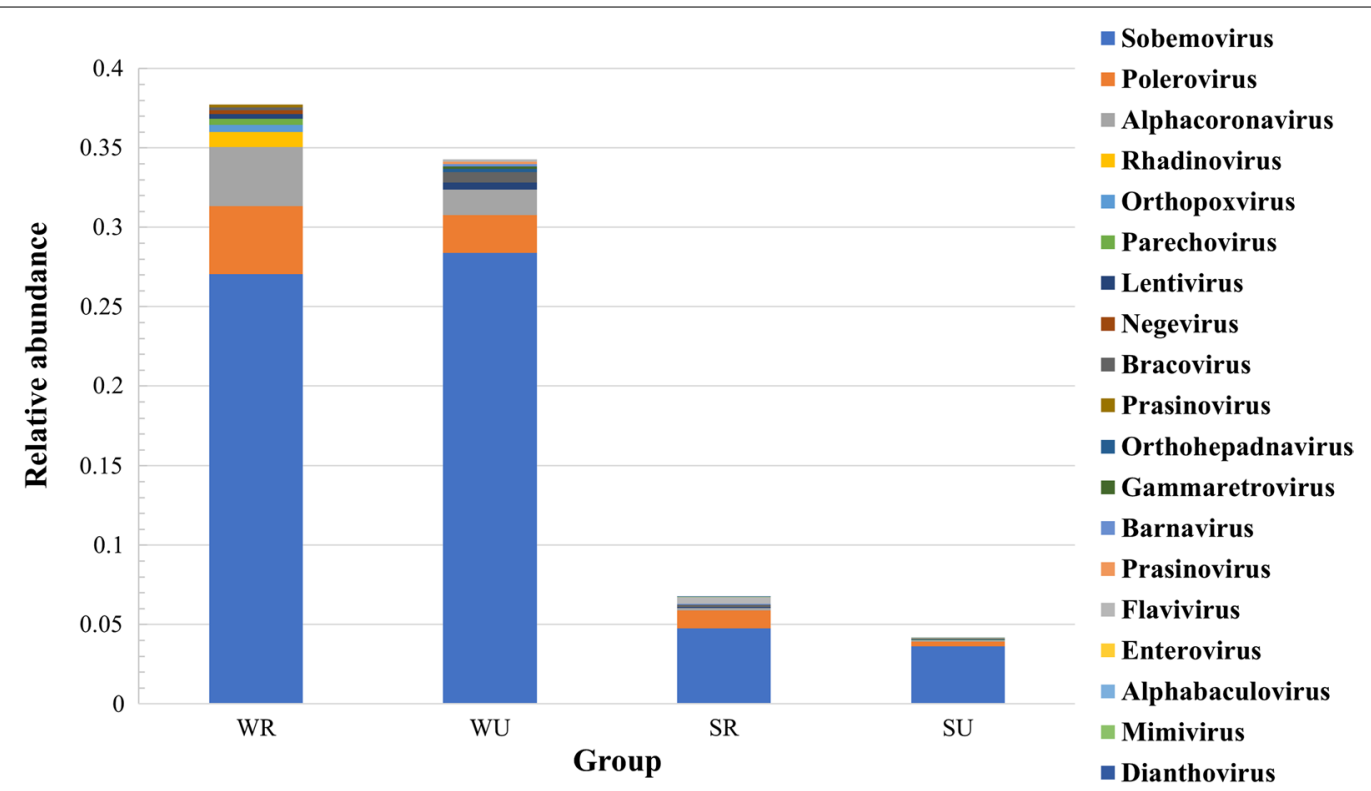

Fig. 5 The top ten viral genera in the different groups of Ae. albopictus. SR: mosquitoes captured in rural areas during summer and autumn; WR: mosquitoes captured in rural areas during winter and spring; SU: mosquitoes captured in urban areas during summer and autumn; WU: mosquitoes captured in urban areas during winter and spring

mosquitoes captured in different areas during the same season showed a high level of similarity (Figs. 1 and 2). However, a previous study revealed a significant difference in the viral communities when comparing mosquitoes captured in different regions [61]. The high level of similarity in viral composition between mosquitoes captured in rural and urban areas in our study might be explained by the following: first, we collected the mosquitoes in urban and rural areas in the same city, and the sampling areas are close, with a maximum straight-line distance between Xiongwei village and Keyuan community of $47 \mathrm{~km}$; second, the large population and active movement of humans in Guangzhou facilitated the spread of Ae. albopictus [30]. 


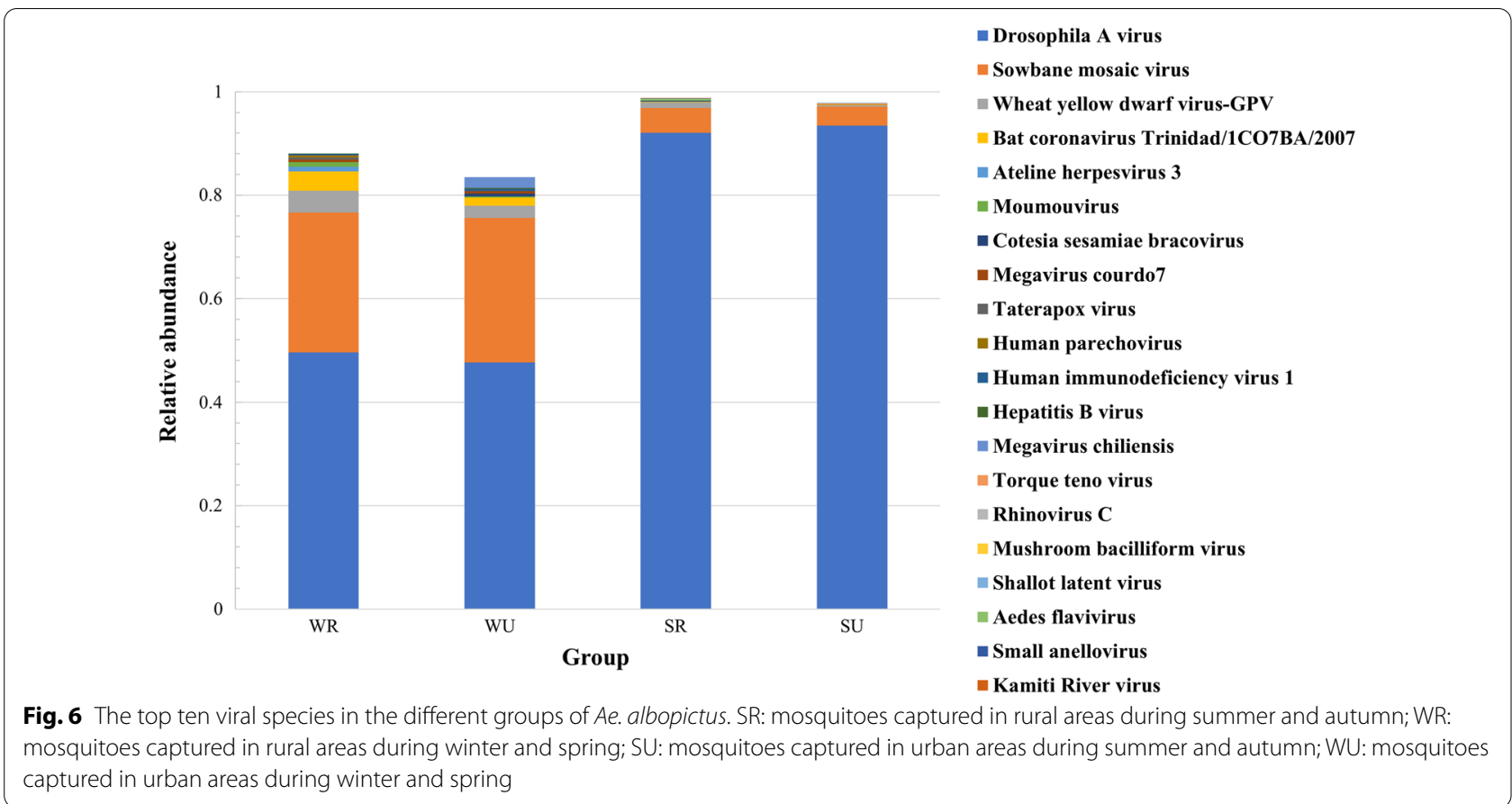

Table 2 Viruses detected in Aedes albopictus

\begin{tabular}{|c|c|c|c|c|c|c|}
\hline Virus & & Xiongwei village & Nanfang village & Yuexiu district & Tianhe district & Total \\
\hline \multirow[t]{3}{*}{ Human parechovirus } & Female & $0(0 / 17)$ & $9.1(2 / 22)$ & $0(0 / 7)$ & $0(0 / 18)$ & $3.1(2 / 64)$ \\
\hline & Male & $11.5(3 / 26)$ & $2.9(1 / 35)$ & $2.9(1 / 34)$ & $5.4(2 / 37)$ & $5.3(7 / 132)$ \\
\hline & Total & $7.0(3 / 43)$ & $5.3(3 / 57)$ & $2.4(1 / 41)$ & $3.6(2 / 55)$ & $4.6(9 / 196)$ \\
\hline \multirow[t]{3}{*}{ Hepatitis B virus } & Female & $0(0 / 17)$ & $0(0 / 22)$ & $0(0 / 7)$ & $5.6(1 / 18)$ & $1.6(1 / 64)$ \\
\hline & Male & $0(0 / 26)$ & $0(0 / 35)$ & $0(0 / 34)$ & $0(0 / 37)$ & $0(0 / 132)$ \\
\hline & Total & $0(0 / 43)$ & $0(0 / 57)$ & $0(0 / 41)$ & $1.8(1 / 55)$ & $0.5(1 / 196)$ \\
\hline
\end{tabular}

Large amounts of the sequences detected in the mosquitoes from our study cannot be annotated to known viral species, and this was consistent with the results of a previous study [63]. It seems that Ae. albopictus harbors a large number of novel viruses, and further studies are required to investigate these unknown viruses. Even though there was only a small proportion of detected sequences that could be annotated as known viruses, more than 50 viral families were annotated in adult $A e$. albopictus, and these viruses were specific to vertebrates, invertebrates, plants, fungi, bacteria, and protozoa. Invertebrate viruses appeared with the highest relative abundance in all samples of Ae. albopictus, which is consistent with the results for Culex mosquitoes [39]. Large numbers of bacteriophages were detected, including members in Myoviridae, Siphoviridae, and Podoviridae [64]. Plant viruses were also found, such as members in Luteoviridae [65]. Some viruses that can cause diseases in humans and animals were detected, indicating the wide range of blood hosts for Ae. albopictus in Guangzhou.

Low temperatures limit insect development and activity, as well as the replication of viruses in insects [66]. Interestingly, the number of viral species in $A e$. albopictus captured in winter and spring was slightly greater than that in Ae. albopictus captured in summer and autumn. In addition, a lower relative abundance of vertebrate viruses was found in Ae. albopictus captured in summer and autumn as compared to that in Ae. albopictus captured in winter and spring. This might be associated with the average winter temperature in Guangzhou $\left(15.9^{\circ} \mathrm{C}\right)$ [67], which is high enough that Ae. albopictus is active all year round in this city. A previous study showed that Ae. albopictus can still feed on humans and animals, and produce eggs in early winter in Guangzhou [68]. In addition, the sex ratio of emerged adults in early winter, such as in November 


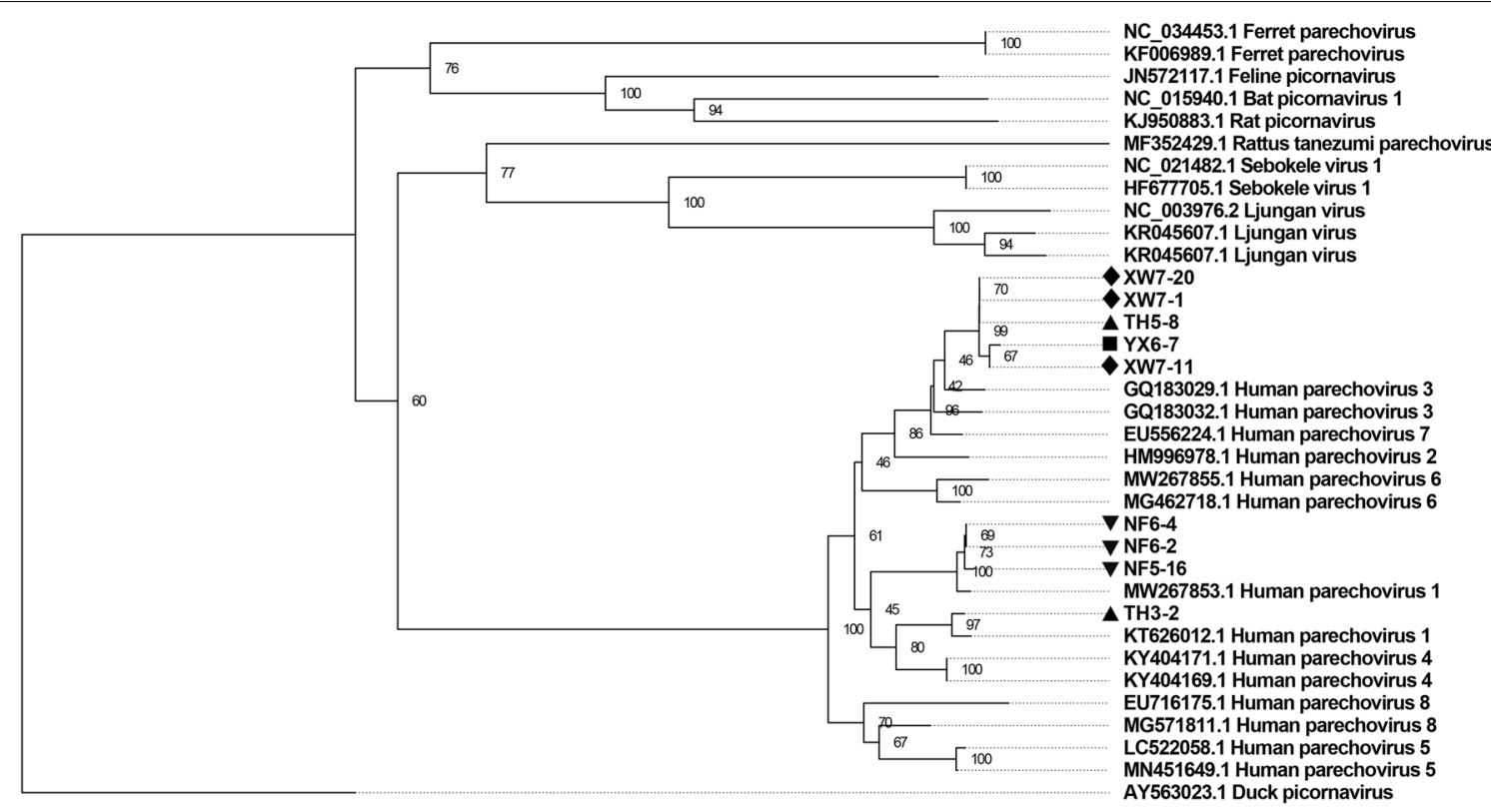

0.04

Fig. 7 The construction of a phylogenetic tree was based on the screening nucleotide sequence of HPeV from Ae. albopictus (MrBayes, GTR $+\mathrm{G}+\mathrm{I}$ nucleotide substitution model). Twenty-five sequences belonging to different species within genus Parechovirus are included for comparison. One sequence belonging to genus Sapelovirus is set as outgroup. Percentages of the posterior probability (PP) values are indicated. $\mathbf{\Delta}$ Sequences detected in mosquitoes trapped in Tianhe district; $\square$ Sequence detected in mosquitoes trapped in Yuexiu district; Sequences detected in mosquitoes trapped in Xiongwei village; $\nabla$ Sequences detected in mosquitoes trapped in Nanfang village
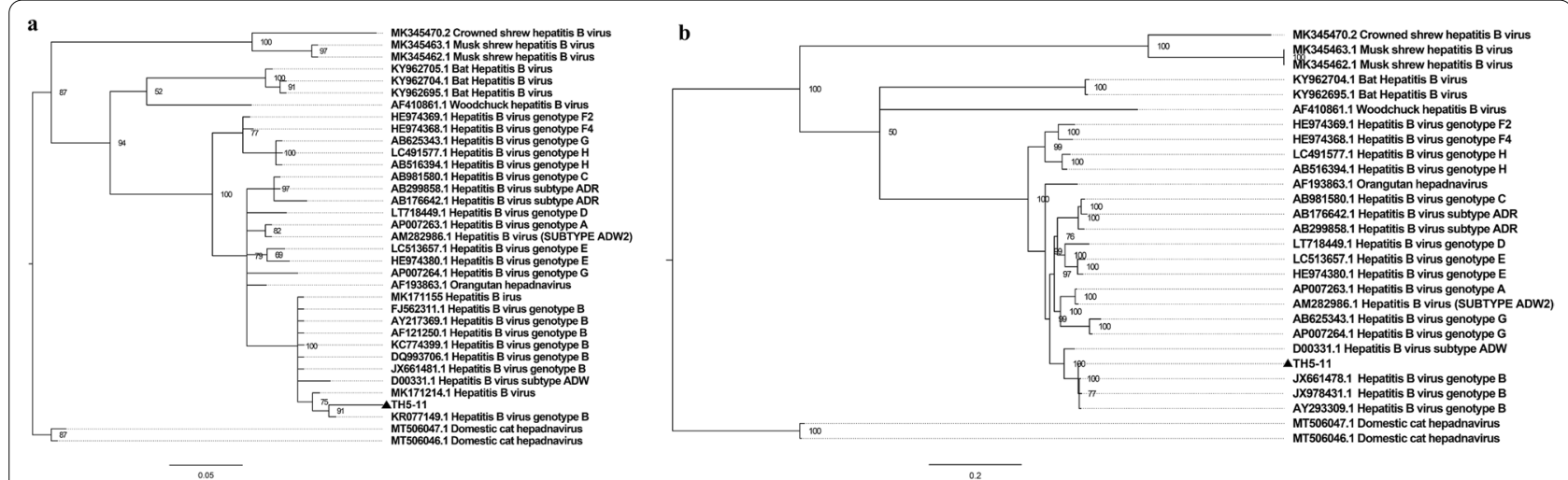

Fig. 8 a The construction of a phylogenetic tree was based on the screening nucleotide sequence of HBV from Ae. albopictus (MrBayes, GTR + G + I nucleotide substitution model). Thirty-two sequences belonging to species Hepatitis $B$ virus are included for comparison. Two sequences belonging to species Domestic cat hepatitis B virus are set as outgroup. Percentages of the posterior probability (PP) values are indicated. $\mathbf{b}$ The construction of a phylogenetic tree was based on the near full-length nucleotide sequence of HBV from Ae. albopictus (MrBayes, GTR + G+I nucleotide substitution model). Twenty-five sequences belonging to species Hepatitis $B$ virus are included for comparison. Two sequences belonging to species Domestic cat hepatitis $B$ virus are set as outgroup. Percentages of the posterior probability (PP) values are indicated. $\mathbf{\Delta}$ Sequences detected in mosquitoes trapped in Tianhe district

(female/male $=1.2)$, is higher than that in some summer months (female/male $=0.71$ in August), indicating that there may be a larger proportion of female Ae. albopictus in winter than in summer [68].
PCR or viral metagenomic analysis indicated that none of the samples was positive for ZIKV, DENV, or CHIKV. This is consistent with the prevalence of the relative diseases in human populations: none of the related mosquito-borne diseases were reported in the sampling 
areas at the time the mosquitoes were captured. In the future, studies should be continued to survey the virome in Ae. albopictus in order to monitor and prevent related mosquito-borne diseases.

Large numbers of vertebrate viruses were detected in our study. Members within Coronaviridae can cause human diseases [69]. Using viral metagenomics, Coronaviridae was found in Ae. albopictus, and it was the most abundant vertebrate viral family in our study. However, none of the samples was positive for it using PCR. This discrepancy might be explained by the high sensitivity of viral metagenomics. A higher relative abundance of Coronaviridae was found in mosquitoes captured during winter and spring. Interestingly, the circulation of coronaviruses in human and animal populations in Guangzhou City also exhibited a peak of coronavirus infection in winter and spring [70]. It seems that xenosurveillance is feasible, and the relative abundance of Coronaviridae in Ae. albopictus can provide some information regarding the disease prevalence in human populations. Bat coronavirus Trinidad/1CO7BA/2007 was the only species detected within Coronaviridae. This virus was first detected in bats in America [71]. Its detection in Ae. albopictus indicated that this virus had already spread to the bats in Guangzhou, China. Some pathogenetic coronaviruses might have originated from bats [72], and therefore, studies on these animals is necessary to prevent the transmission of emerging viruses.

A previous study reported the detection of Herpesviridae in Culex mosquitoes [61]. In our study, Herpesviridae was the second most abundant vertebrate viral family in Ae. albopictus. Different species of herpesviruses were detected, including Ateline herpesvirus 3, Macacine herpesvirus 1, Caviid herpesvirus 2, Gallid herpesvirus 1, Human herpesvirus 6, and Human herpesvirus 6B, suggesting that many animals in Guangzhou were infected by herpesviruses. Like Coronaviridae, a higher relative abundance of Herpesviridae was found in Ae. albopictus captured in winter and spring than that in Ae. albopictus captured in summer and autumn, which might be explained by the seasonal dynamics of herpesviruses in human and animal populations [73].

Sequences annotated as Anelloviridae have been detected in other species of mosquitoes, such as Anopheles mosquitoes [62]. Three members of Anelloviridae were annotated in our study, including Torque teno virus, Small anellovirus, and Torque teno sus virus 1 , indicating that humans and pigs in Guangzhou were infected by anelloviruses. However, PCR results indicated that none of the mosquito pools was positive for TTV, which might also be explained by the high sensitivity of viral metagenomics. The pathogenicity of TTV is still unknown, but it is prevalent in humans [74], and mother-to-infant vertical transmission of this virus is known to occur [75]. Studies should be performed to investigate the relationship between TTV and human diseases. Pigs are often co-infected with torque teno sus virus and other viruses, especially the porcine circovirus, and it may pose a potential threat to swine herds [39].

Like Coronaviridae and Herpesviridae, a higher relative abundance of Picornaviridae was also found in mosquitoes captured in winter and spring. A similar seasonal pattern for picornaviruses was found in some blood hosts of Ae. albopictus [76]. Three viral species within Picornaviridae were detected, including Human parechovirus, Rhinovirus $C$, and Oscivirus A. $\mathrm{HPeV}$ and rhinovirus $\mathrm{C}$ are human pathogenic viruses related to gastrointestinal diseases and respiratory diseases, respectively [77]. It seems that humans in Guangzhou were infected by parechovirus and rhinovirus, and it would be a worthy endeavor to further study these viruses for disease prevention and control. Osciviruses originate from amphibians and birds [78, 79], suggesting that Ae. albopictus also feeds on these animals. The PCR results indicated that nine pooled samples were positive for $\mathrm{HPeV}$. The $\mathrm{HPeV}$ sequences obtained in our study were clustered with $\mathrm{HPeV} 1$ and 3 sequences. HPeV 1 can cause acute gastroenteritis, and it is the most frequently identified member within the genus Parechovirus [80-82]. Disease outbreak related to HPeV 3 has been reported in humans [83]. To prevent the relative diseases in Guangzhou, mosquito surveillance is beneficial because it can provide rapid identification of the spread of emerging $\mathrm{HPeV}$ types. In our study, most of the $\mathrm{HPeV}$ sequences were detected in male mosquitoes. Male Ae. albopictus do not need a blood meal, and it was unlikely that they acquired this virus from humans by mosquito bite. Male Ae. albopictus might have acquired $\mathrm{HPeV}$ by vertical transmission or from the environment, such as from raw sewage [84]. However, there is no evidence indicating that $\mathrm{HPeV}$ can be transmitted vertically. Thus, it is likely that the $\mathrm{HPeV}$ in male Ae. albopictus was obtained from the environment. Surveillance of the virome in mosquitoes not only provides data that reflects the viral infection status in humans and animals, but also provides information regarding the viruses in the environment.

Hepatitis $B$ virus was the only viral species within Hepadnaviridae detected by viral metagenomics. A higher relative abundance of Hepatitis $B$ virus was found in mosquitoes captured during winter and spring than that in mosquitoes captured during summer and autumn, which may be explained by the seasonal fluctuations in HBV DNA levels in humans [85]. PCR results indicated that one female mosquito pool collected in an urban area was positive for HBV, and the first near fulllength genome of HBV (TH5-11) from mosquitoes was 
amplified. The screening sequence and the near fulllength genome showed a high level of similarity with human HBV genotype B sequences. A previous study reported that HBV genotype B is common in Asia [86], and the results in our study similarly indicated that HBV genotype B is prevalent in humans in Guangzhou. Mosquito bites may transmit HBV to laboratory animals [87]. However, up until now, there is no evidence showing that mosquitoes can transmit HBV to humans. Even though we amplified the near full-length genome of HBV in the current study, the most likely explanation for this detection is that the mosquitoes fed on HBV-infected humans. Experiments are needed to determine the role of Ae. albopictus in HBV transmission.

This research can further our understanding of the virome in adult Ae. albopictus in Guangzhou City. We also demonstrated that there is a wide circulation of diverse vertebrate viruses in Ae. albopictus. In addition, the relative abundance of vertebrate viruses in Ae. albopictus was in accordance with the disease prevalence in humans and animals, suggesting that surveillance of the virome in adult Ae. albopictus not only provides information to prevent mosquito-borne diseases but also forms a framework for the surveillance, prevention, and control of other human diseases. Surveillance of the virome in Ae. albopictus can also provide information regarding the viruses in the environment.

There are some limitations to our study. First, we did not pool the mosquitoes by sex in our viral metagenomic studies, which might affect the viral community composition within them. Second, midgut and salivary gland dissections were not performed to identify where the viruses were located. Third, the head, legs, and wings of the mosquitoes were not removed in our study. In the future, mosquito heads, legs, and wings should be removed to prevent PCR inhibition and reduce the host genome. Our findings should be confirmed by more rigorous studies with larger sample sizes.

\section{Conclusions}

This study revealed the viral composition of adult Ae. albopictus captured in different areas and during different seasons in Guangzhou City. The viral composition in Ae. albopictus varied mainly between seasons. A higher relative abundance of some vertebrate viruses was found in the mosquitoes trapped in winter and spring, which was consistent with the seasonal patterns of the related viruses in humans and animals. $\mathrm{HPeV}$ and HBV were detected in Ae. albopictus using PCR. Although the first near full-length genome of HBV from Ae. albopictus was amplified, additional research is still needed to decipher whether Ae. albopictus plays a role in the transmission of HBV. In the future, surveillance of the virome in Ae. albopictus should be continued to provide information for the prevention and control of mosquito-borne diseases. In addition, xenosurveillance is feasible, and the surveillance of the virome in Ae. albopictus can also form a framework for surveillance, prevention, and control of other human diseases.

\section{Abbreviations}

Ae. albopictus: Aedes albopictus; CHIKV: Chikungunya virus; DENV: Dengue virus; HBV: Hepatitis B virus; HPeV: Human parechovirus; NCBI NT database: National Center for Biotechnology Information nucleotide database; NCBI NR database: National Center for Biotechnology Information non-redundant protein sequence database; ORFs: Open reading frames; PBS: Phosphate-buffered saline; PCA: Principal component analysis; PCoA: Principal coordinates analysis; PP: Posterior probability; TTV: Torque teno virus; YFV: Yellow fever virus; ZIKV: Zika virus.

\section{Supplementary Information}

The online version contains supplementary material available at https://doi. org/10.1186/s13071-021-04922-z.

Additional file 1: Table S1. Mosquitoes pooled for viral metagenomic analysis. Table S2. Mosquito pools for viral detection using PCR. Table S3. Sequencing results of viral metagenomics

Additional file 2: Table S4. Nucleotide sequence identity for the near full-length genomic sequences of hepatitis B virus (HBV) from Aedes albopictus, humans, bats and woodchuck.

Acknowledgements

We are grateful to Hongbiao Chen, Xueshan Zhong, Shaowei Chen, Xueyan Zheng, Xuejiao Chen, and Yongzhi Li for their participation in the collection of samples.

\section{Authors' contributions}

WH, YC, and QC conceived the project. WH and QC contributed to the writing of the paper. $Y C, H H$, and $Y G$ performed laboratory experiments for viral metagenomics. WH and $Y G$ performed viral detection and sequencing. WH and YC performed bioinformatics analysis. YC, XZ, YG, MP, DX, HH, JC, JZ, and ZL performed sample collection. All of the authors have read and approved the manuscript for publication.

\section{Funding}

This work was funded by the Key-Area Research and Development Program of Guangdong Province (2018B020241002). The funding organization had no role in the study design, data collection and analysis, decision to publish, or preparation of the manuscript.

Availability of data and material

All of the data generated or analyzed during this study are included in this manuscript and the supplementary information files. Sequences of HBV and HPeV were uploaded to the NCBI database (GenBank accession numbers: MW455086-MW455091, MZ502310-MZ502312 and MW411446). The viral metagenomic data were uploaded to the NCBI Sequence Read Archive (SRA) repository (SRA number: SRP304029).

\section{Declarations}

\section{Ethics approval and consent to participate}

The protocol of this study was approved by the Animal Ethics and Welfare Committee of the School of Public Health, Southern Medical University.

Consent for publication

Not applicable. 


\section{Competing interests}

The authors declare that they have no competing interests.

Received: 13 February 2021 Accepted: 3 August 2021 Published online: 18 August 2021

\section{References}

1. Servadio JL, Rosenthal SR, Carlson L, Bauer C. Climate patterns and mosquito-borne disease outbreaks in South and Southeast Asia. J Infect Public Health. 2018;11(4):566-71. https://doi.org/10.1016/j.jiph.2017.12. 006.

2. Gratz NG. Critical review of the vector status of Aedes albopictus. Med Vet Entomol. 2004;18(3):215-27. https://doi.org/10.1111/j.0269-283X.2004. 00513.x.

3. Kraemer MU, Sinka ME, Duda KA, Mylne AQ, Shearer FM, Barker CM. The global distribution of the arbovirus vectors Aedes aegypti and Ae. albopictus. Elife. 2015;4:e08347. https://doi.org/10.7554/eLife.08347.

4. Tancredi A, Papandrea D, Marconcini M. Tracing temporal and geographic distribution of resistance to pyrethroids in the arboviral vector Aedes albopictus. PLoS Negl Trop Dis. 2020;14(6):e0008350. https://doi.org/10. 1371/journal.pntd.0008350.

5. Benedict MQ, Levine RS, Hawley WA, Lounibos LP. Spread of the tiger: global risk of invasion by the mosquito Aedes albopictus. Vector Borne Zoonotic Dis (Larchmont, NY). 2007;7(1):76-85. https://doi.org/10.1089/ vbz.2006.0562.

6. Lounibos LP, Kramer LD. Invasiveness of Aedes aegypti and Aedes albopictus and vectorial capacity for chikungunya virus. J Infect Dis. 2016;214(suppl 5):S453-8. https://doi.org/10.1093/infdis/jiw285.

7. Bohers C, Mousson L, Madec Y, Vazeille M, Rhim A, M'Ghirbi Y, et al. The recently introduced Aedes albopictus in Tunisia has the potential to transmit chikungunya, dengue and Zika viruses. PLoS Negl Trop Dis. 2020;14(10):e0008475. https://doi.org/10.1371/journal.pntd.0008475.

8. Swan T, Russell TL, Burkot TR, Liu J, Ritchie SA, Staunton KM. The effect of sound lure frequency and habitat type on male Aedes albopictus (Diptera: Culicidae) capture rates with the male Aedes sound trap. J Med Entomol. 2020. https://doi.org/10.1093/jme/tjaa242.

9. Renault P, Solet JL, Sissoko D, Balleydier E, Larrieu S, Filleul L, et al. A major epidemic of chikungunya virus infection on Reunion Island, France, 2005-2006. Am J Trop Med Hyg. 2007;77(4):727-31.

10. Ali AA, Bajric B, Isache CL, Maharaj RP. Mosquito borne illness in a Floridian hiker. Am J Emerg Med. 2020. https://doi.org/10.1016/j.ajem.2020.12.008.

11. Dang TT, Pham MH, Bui HV, Le DV. First full-length genome sequence of dengue virus serotype 2 circulating in Vietnam in 2017. Infection and drug resistance. 2020;13:4061-8. https://doi.org/10.2147/idr.s275645.

12. Lim JT, Han Y, Dickens BSL, Choo ELW, Chew LZX, Cook AR. Revealing two dynamic dengue epidemic clusters in Thailand. BMC Infect Dis. 2020;20(1):927. https://doi.org/10.1186/s12879-020-05666-4.

13. Du J, Zhang L, Hu X, Peng R, Wang G, Huang Y, et al. Phylogenetic analysis of the dengue virus strains causing the 2019 dengue fever outbreak in Hainan, China. Virol Sin. 2021. https://doi.org/10.2147/idr.s275645/10. 1007/s12250-020-00335-x.

14. Edgerton SV, Thongsripong P, Wang C, Montaya M, Balmaseda A, Harris E, et al. Evolution and epidemiologic dynamics of dengue virus in Nicaragua during the emergence of chikungunya and Zika viruses. PLoS ONE. 2020. https://doi.org/10.1016/j.meegid.2020.104680.

15. Morris JK, Dolk H, Durán P, Orioli IM. Use of infectious disease surveillance reports to monitor the Zika virus epidemic in Latin America and the Caribbean from 2015 to 2017: strengths and deficiencies. BMJ Open 2020;10(12):e042869. https://doi.org/10.1136/bmjopen-2020-042869.

16. Calvet GA, Kara EO, Landoulsi S, Habib N, Bôtto-Menezes CHA, Franca RFO, et al. Cohort profile: study on Zika virus infection in Brazil (ZIKABRA study). PLOS ONE. 2021;16(1):e0244981. https://doi.org/10.1371/journal. pone.0244981.

17. Zheng J, Yin Y, Li B. A new scheme for climate regionalization in China. Acta Geograph Sin. 2010;65:3-13.

18. Kamal M, Kenawy MA, Rady MH, Khaled AS, Samy AM. Mapping the global potential distributions of two arboviral vectors Aedes aegypti and Ae. albopictus under changing climate. PLOS ONE. 2018;13(12):e0210122. https://doi.org/10.1371/journal.pone.0210122.
19. Huber JH, Childs ML, Caldwell JM, Mordecai EA. Seasonal temperature variation influences climate suitability for dengue, chikungunya, and Zika transmission. PLoS Negl Trop Dis. 2018;12(5):e0006451. https://doi.org/10. 1371/journal.pntd.0006451.

20. Wu F, Liu Q, Lu L, Wang J, Song X, Ren D. Distribution of Aedes albopictus (Diptera: Culicidae) in northwestern China. Vector Borne Zoonotic Dis (Larchmont, NY). 2011;11(8):1181-6. https://doi.org/10.1089/vbz.2010. 0032.

21. Qiu FX, Gubler DJ, Liu JC, Chen QQ. Dengue in China: a clinical review. Bull World Health Organ. 1993;71(3-4):349-59.

22. Sun J, Lu L, Wu H, Yang J, Xu L, Sang S, et al. Epidemiological trends of dengue in mainland China, 2005-2015. Int J Infect Dis IJID. 2017;57:8691. https://doi.org/10.1016/j.ijid.2017.02.007.

23. Qiaoli Z, Jianfeng H, De W, Zijun W, Xinguang Z, Haojie Z, et al. Maiden outbreak of chikungunya in Dongguan city, Guangdong province, China: epidemiological characteristics. PLoS ONE. 2012;7(8):e42830. https://doi. org/10.1371/journal.pone.0042830.

24. Luo $L$, Jiang $L Y$, Xiao XC, Di B, Jing $Q L$, Wang $S Y$, et al. The dengue preface to endemic in mainland China: the historical largest outbreak by Aedes albopictus in Guangzhou, 2014. Infect Dis Poverty. 2017;6(1):148. https:// doi.org/10.1186/s40249-017-0352-9.

25. Yan H, Ding Z, Yan J, Yao W, Pan J, Yang Z, et al. Epidemiological characterization of the 2017 dengue outbreak in Zhejiang, China and molecular characterization of the viruses. Front Cell Infect Microbiol. 2018;8:216. https://doi.org/10.3389/fcimb.2018.00216.

26. Yang T, Lu L, Fu G, Zhong S, Ding G, Xu R, et al. Epidemiology and vector efficiency during a dengue fever outbreak in Cixi, Zhejiang Province, China. J Vector Ecol J Soc Vector Ecol. 2009;34(1):148-54. https://doi.org/ 10.1111/j.1948-7134.2009.00018.x.

27. Lu X, Li X, Mo Z, Jin F, Wang B, Huang J, et al. Chikungunya emergency in China: microevolution and genetic analysis for a local outbreak. Virus Genes. 2014;48(1):15-22. https://doi.org/10.1007/s11262-013-0991-2.

28. Pan J, Fang C, Yan J, Yan H, Zhan B, Sun Y, et al. Chikungunya fever outbreak, Zhejiang Province, China, 2017. Emerg Infect Dis. 2019;25(8):158991. https://doi.org/10.3201/eid2508.181212.

29. Gao JP, Chen HM, Shi H, Peng H, Ma YJ. Correlation between adult pyrethroid resistance and knockdown resistance $(k d r)$ mutations in Aedes albopictus (Diptera: Culicidae) field populations in China. Infect Dis Poverty. 2018;7(1):86. https://doi.org/10.1186/s40249-018-0471-y.

30. Pei J, Niu Z, Wang L, Song XP, Huang N, Geng J, et al. Spatial-temporal dynamics of carbon emissions and carbon sinks in economically developed areas of China: a case study of Guangdong Province. Scientific reports. 2018;8 1:13383. https://doi.org/10.1038/s41598-018-31733-7.

31. Yin Q, Li L, Guo X, Wu R, Shi B, Wang Y, et al. A field-based modeling study on ecological characterization of hourly host-seeking behavior and its associated climatic variables in Aedes albopictus. Parasites Vectors. 2019;12(1):474. https://doi.org/10.1186/s13071-019-3715-1.

32. Cheng Q, Jing Q, Spear RC, Marshall JM, Yang Z, Gong P. The interplay of climate, intervention and imported cases as determinants of the 2014 dengue outbreak in Guangzhou. PLoS Negl Trop Dis. 2017;11(6):e0005701. https://doi.org/10.1371/journal.pntd.0005701.

33. Zheng X, Zhong D, He Y, Zhou G. Seasonality modeling of the distribution of Aedes albopictus in China based on climatic and environmental suitability. Infect Dis Poverty. 2019;8(1):98. https://doi.org/10.1186/ s40249-019-0612-y.

34. Lai S, Huang Z, Zhou H, Anders KL, Perkins TA, Yin W, et al. The changing epidemiology of dengue in China, 1990-2014: a descriptive analysis of 25 years of nationwide surveillance data. BMC Med. 2015;13:100. https://doi. org/10.1186/s12916-015-0336-1.

35. Feng X, Sun W, Birkhead GS, Wang X, Guo Z, Lu J. The surveillance of four mosquito-borne diseases in international travelers arriving at Guangzhou Baiyun International Airport, China, 2016-2017. Travel Med Infect Dis. 2019. https://doi.org/10.1016/j.tmaid.2019.101513.

36. Alquezar-Planas DE, Mourier T, Bruhn CA, Hansen AJ, Vitcetz SN, Mørk $\mathrm{S}$, et al. Discovery of a divergent HPIV4 from respiratory secretions using second and third generation metagenomic sequencing. Sci Rep. 2013;3:2468. https://doi.org/10.1038/srep02468.

37. Cholleti H, Hayer J, Abilio AP, Mulandane FC, Verner-Carlsson J, Falk Kl, et al. Discovery of novel viruses in mosquitoes from the Zambezi Valley of Mozambique. PLoS ONE. 2016;11(9):e0162751. https://doi.org/10.1371/ journal.pone.0162751. 
38. Levy SE, Myers RM. Advancements in next-generation sequencing. Annu Rev Genomics Hum Genet. 2016;17:95-115. https://doi.org/10.1146/ annurev-genom-083115-022413.

39. Shi C, Liu Y, Hu X, Xiong J, Zhang B, Yuan Z. A metagenomic survey of viral abundance and diversity in mosquitoes from Hubei province. PLOS ONE. 2015;10(6):e0129845. https://doi.org/10.1371/journal.pone.0129845.

40. da Costa CF, da Silva AV, Do Nascimento VA, de Souza VC, Monteiro D, Terrazas WCM, et al. Evidence of vertical transmission of Zika virus in fieldcollected eggs of Aedes aegypti in the Brazilian Amazon. PLoS NegI Trop Dis. 2018;12(7):e0006594. https://doi.org/10.1371/journal.pntd.0006594.

41. Naveca FG, Akıner MM, Öztürk M, Başer AB, Günay F, Hacıoğlu S, et al. Arboviral screening of invasive Aedes species in northeastern Turkey: West Nile virus circulation and detection of insect-only viruses. PLoS Negl Trop Dis. 2019;13(5):e0007334. https://doi.org/10.1371/journal.pntd.0007334.

42. Aranda C, Martínez MJ, Montalvo T, Eritja R, Navero-Castillejos J, Herreros E, et al. Arbovirus surveillance: first dengue virus detection in local Aedes albopictus mosquitoes in Europe, Catalonia, Spain, 2015. Euro Surveill Bull Eur sur Les Mal Transm Eur Commun Dis Bull. 2018. https://doi.org/10. 2807/1560-7917.es.2018.23.47.1700837.

43. He X, Yin Q, Zhou L, Meng L, Hu W, Li F, et al. Metagenomic sequencing reveals viral abundance and diversity in mosquitoes from the ShaanxiGansu-Ningxia region, China. PLoS Negl Trop Dis. 2021;15(4):e0009381. https://doi.org/10.1371/journal.pntd.0009381.

44. Wu D, Tan Q, Zhang H, Huang P, Zhou H, Zhang X, et al. Genomic and biological features of a novel orbivirus isolated from mosquitoes, in China. Virus Res. 2020;285: 197990. https://doi.org/10.1016/j.virusres.2020. 197990.

45. Kubacki J, Flacio E, Qi W, Guidi V. Viral metagenomic analysis of Aedes albopictus mosquitos from Southern Switzerland. Viruses. 2020;12(9):929. https://doi.org/10.3390/v12090929.

46. Yadav KK, Datta S, Naglot A, Bora A, Hmuaka V, Bhagyawant S, et al. Diversity of cultivable midgut microbiota at different stages of the Asian Tiger mosquito, Aedes albopictus from Tezpur, India. PLoS ONE. 2016;11(12):e0167409. https://doi.org/10.1371/journal.pone.0167409.

47. Kubacki J, Flacio E, Qi W, Guidi V, Tonolla M, Fraefel C. Viral metagenomic analysis of Aedes albopictus mosquitos from Southern Switzerland. Viruses. 2020. https://doi.org/10.3390/v12090929.

48. Ergünay K, Litzba N, Brinkmann A, Günay F, Sarıkaya Y, Kar S, et al. Cocirculation of West Nile virus and distinct insect-specific flaviviruses in Turkey. Parasites Vectors. 2017;10(1):149. https://doi.org/10.1186/ s13071-017-2087-7.

49. Allander T, Tammi MT, Eriksson M, Bjerkner A, Tiveljung-Lindell A, Andersson $\mathrm{B}$. Cloning of a human parvovirus by molecular screening of respiratory tract samples. Proc Natl Acad Sci USA. 2005;102(36):12891-6. https:// doi.org/10.1073/pnas.0504666102.

50. Naccache SN, Federman S, Veeraraghavan N, Zaharia M, Lee D, Samayoa E, et al. A cloud-compatible bioinformatics pipeline for ultrarapid pathogen identification from next-generation sequencing of clinical samples. Genome Res. 2014;24(7):1180-92. https://doi.org/10.1101/gr.171934.113.

51. Peng Y, Leung HC, Yiu SM, Chin FY. IDBA-UD: a de novo assembler for single-cell and metagenomic sequencing data with highly uneven depth. Bioinformatics (Oxford, England). 2012;28(11):1420-8. https://doi. org/10.1093/bioinformatics/bts174.

52. Drexler JF, Geipel A, König A, Corman VM, van Riel D, Leijten LM, et al. Bats carry pathogenic hepadnaviruses antigenically related to hepatitis B virus and capable of infecting human hepatocytes. Proc Natl Acad Sci USA. 2013;110(40):16151-6. https://doi.org/10.1073/pnas.1308049110.

53. Abundes-Gallegos J, Salas-Rojas M, Galvez-Romero G, Perea-Martínez L, Obregón-Morales CY, Morales-Malacara JB, et al. Detection of dengue virus in bat flies (Diptera: Streblidae) of common vampire bats, Desmodus rotundus, in Progreso, Hidalgo, Mexico. Vector Borne Zoonotic Dis (Larchmont, NY). 2018;18(1):70-3. https://doi.org/10.1089/vbz.2017.2163.

54. Harvala H, Robertson I, McWilliam Leitch EC, Benschop K, Wolthers KC, Templeton K, et al. Epidemiology and clinical associations of human parechovirus respiratory infections. J Clin Microbiol. 2008;46(10):3446-53. https://doi.org/10.1128/jcm.01207-08.

55. Jalali H, Mahdavi MR, Zaeromali N. Torque Teno Virus (TTV) among $\beta$-thalassemia and haemodialysis patients in Mazandaran Province (North of Iran). Int J Mol Cell Med. 2017;6(1):56-60.

56. VanDevanter DR, Warrener P, Bennett L, Schultz ER, Coulter S, Garber RL, et al. Detection and analysis of diverse herpesviral species by consensus primer PCR. J Clin Microbiol. 1996;34(7):1666-71. https://doi.org/10.1128/ jcm.34.7.1666-1671.1996.

57. Falcón A, Vázquez-Morón S, Casas I, Aznar C, Ruiz G, Pozo F, et al. Detection of alpha and betacoronaviruses in multiple Iberian bat species. Adv Virol. 2011;156(10):1883-90. https://doi.org/10.1007/s00705-011-1057-1.

58. Huo SMY, Shi Y, Xiong Y, Li D, Qiu M, Zheng X, Chen S, Jiang L, Chen Q. A survey of chikungunya virus in brain tissue samples from rat like animals in Xiamen, Shenzhen and Guangzhou. J Pract Med. 2017;33(5):820-2.

59. Wu JY, Lun ZR, James AA, Chen XG. Dengue fever in mainland China. Am J Trop Med Hyg. 2010;83(3):664-71. https://doi.org/10.4269/ajtmh.2010. 09-0755.

60. Cantalupo PG, Pipas JM. Detecting viral sequences in NGS data. Curr Opin Virol. 2019;39:41-8. https://doi.org/10.1016/j.coviro.2019.07.010.

61. Atoni E, Wang Y, Karungu S, Waruhiu C, Zohaib A, Obanda V, et al. Metagenomic Virome analysis of Culex mosquitoes from Kenya and China. Viruses. 2018. https://doi.org/10.3390/v10010030.

62. Xia H, Wang Y, Shi C, Atoni E, Zhao L, Yuan Z. Comparative metagenomic profiling of viromes associated with four common mosquito species in China. Virol Sin. 2018;33(1):59-66. https://doi.org/10.1007/ s12250-018-0015-4

63. Ng TF, Willner DL, Lim YW, Schmieder R, Chau B, Nilsson C, et al. Broad surveys of DNA viral diversity obtained through viral metagenomics of mosquitoes. PLoS ONE. 2011;6(6):e20579. https://doi.org/10.1371/journal. pone.0020579.

64. Brown TL, Ku H, Mnatzaganian G, Angove M, Petrovski S, Kabwe M. The varying effects of a range of preservatives on Myoviridae and Siphoviridae bacteriophages formulated in a semi-solid cream preparation. Lett Appl Microbiol. 2020;71(2):203-9. https://doi.org/10.1111/lam.13299.

65. Heck M, Brault V. Targeted disruption of aphid transmission: a vision for the management of crop diseases caused by Luteoviridae members. Curr Opin Virol. 2018:33:24-32. https://doi.org/10.1016/j.coviro.2018.07.007.

66. Tsunoda T, Chaves LF, Nguyen GT, Nguyen YT, Takagi M. Winter activity and diapause of Aedes albopictus (Diptera: Culicidae) in Hanoi, Northern Vietnam. J Med Entomol. 2015;52(6):1203-12. https://doi.org/10.1093/ jme/tjv122.

67. Ou CQ, Song YF, Yang J, Chau PY, Yang L, Chen PY, et al. Excess winter mortality and cold temperatures in a subtropical city, Guangzhou, China. PLoS ONE. 2013;8(10):e77150. https://doi.org/10.1371/journal.pone.00771 50.

68. Yang D, He Y, Ni W, Lai Q, Yang Y, Xie J, et al. Semi-field life-table studies of Aedes albopictus (Diptera: Culicidae) in Guangzhou, China. PLoS ONE. 2020;15(3):e0229829. https://doi.org/10.1371/journal.pone.0229829.

69. Hu B, Ge X, Wang LF, Shi Z. Bat origin of human coronaviruses. Virol J. 2015;12:221. https://doi.org/10.1186/s12985-015-0422-1.

70. Killerby ME, Biggs HM, Haynes A, Dahl RM, Mustaquim D, Gerber SI, et al. Human coronavirus circulation in the United States 2014-2017. J Clin Virol. 2018;101:52-6. https://doi.org/10.1016/j.jcv.2018.01.019.

71. Carrington CV, Foster JE, Zhu HC, Zhang JX, Smith GJ, Thompson N, et al. Detection and phylogenetic analysis of group 1 coronaviruses in South American bats. Emerg Infect Dis. 2008;14(12):1890-3. https://doi.org/10. 3201/eid1412.080642.

72. Cui JA-O, Li F, Shi ZA-OX. Origin and evolution of pathogenic coronaviruses. Nat Rev Microbiol. 2018;17(3):181-92. https://doi.org/10.1038/ s41579-018-0118-9.

73. Bakker KM, Martinez-Bakker ME. Digital epidemiology reveals global childhood disease seasonality and the effects of immunization. Proc Natl Acad Sci USA. 2016;113(24):6689-94. https://doi.org/10.1073/pnas.15239 41113.

74. Spandole S, Cimponeriu D, Berca LM, Mihăescu G. Human anelloviruses: an update of molecular, epidemiological and clinical aspects. Adv Virol. 2015;160(4):893-908. https://doi.org/10.1007/s00705-015-2363-9.

75. Xin X, Xiaoguang Z, Ninghu Z, Youtong L, Liumei X, Boping Z. Motherto-infant vertical transmission of transfusion transmitted virus in South China. J Perinat Med. 2004;32(5):404-6. https://doi.org/10.1515/jpm.2004. 136.

76. Chiang GPK, Chen Z, Chan MCW, Lee SHM, Kwok AK, Yeung ACM, et al. Clinical features and seasonality of parechovirus infection in an Asian subtropical city, Hong Kong. PLOS ONE. 2017;12(9):e0184533. https://doi. org/10.1371/journal.pone.0184533.

77. Jacobs SE, Lamson DM, St George K, Walsh TJ. Human rhinoviruses. Clin Microbiol Rev. 2013;26(1):135-62. https://doi.org/10.1128/cmr.00077-12. 
78. Pankovics P, Boros Á, Tóth Z, Phan TG, Delwart E, Reuter G. Genetic characterization of a second novel picornavirus from an amphibian host, smooth newt (Lissotriton vulgaris). Adv Virol. 2017;162(4):1043-50. https://doi.org/10.1007/s00705-016-3198-8.

79. Woo PC, Lau SK, Huang Y, Lam CS, Poon RW, Tsoi HW, et al. Comparative analysis of six genome sequences of three novel picornaviruses, turdiviruses 1,2 and 3, in dead wild birds, and proposal of two novel genera, Orthoturdivirus and Paraturdivirus, in the family Picornaviridae. J Gen Virol. 2010:91(Pt 10):2433-48. https://doi.org/10.1099/vir.0.021717-0.

80. Shokrollahi MR, Noorbakhsh S, Monavari HR, Ghavidel Darestani S, Vosoughi Motlagh A, Javadi NS. Acute nonbacterial gastroenteritis in hospitalized children: a cross sectional study. Jundishapur J Microbiol. 2014;7(12):e11840. https://doi.org/10.5812/jjm.11840.

81. Romero JR, Selvarangan R. The human Parechoviruses: an overview. Adv Pediatr. 2011;58(1):65-85. https://doi.org/10.1016/j.yapd.2011.03.008.

82. Tanaka S, Aoki Y, Matoba Y, Yahagi K, Itagaki T, Matsuzaki Y, et al. Seroepidemiology of human parechovirus types 1, 3, and 6 in Yamagata, Japan, in 2014. Microbiol Immunol. 2016;60(12):854-8. https://doi.org/10.1111/ 1348-0421.12456.

83. McNeale D, Wang CYT, Arden KE, Mackay IM. HPeV-3 predominated among Parechovirus A positive infants during an outbreak in 2013-2014 in Queensland, Australia. J Clin Virol. 2018;98:28-32. https://doi.org/10. 1016/j.jcv.2017.12.003.

84. Lodder WJ, Wuite M, de Roda Husman AM, Rutjes SA. Environmental surveillance of human parechoviruses in sewage in The Netherlands. Appl Environ Microbiol. 2013;79(20):6423-8. https://doi.org/10.1128/aem. 01917-13.

85. Farnik H, Bojunga J, Berger A, Allwinn R, Waidmann O, Kronenberger B, et al. Low vitamin $D$ serum concentration is associated with high levels of hepatitis $B$ virus replication in chronically infected patients. Hepatology (Baltimore, MD). 2013;58(4):1270-6. https://doi.org/10.1002/hep.26488.

86. Rasche A, Souza B, Drexler JF. Bat hepadnaviruses and the origins of primate hepatitis B viruses. Curr Opin Virol. 2016;16:86-94. https://doi. org/10.1016/j.coviro.2016.01.015.

87. Zheng Y, Liu D, Feng D, Tang H, Li Y, You X. An animal study on transmission of hepatitis B virus through mosquitoes. Chin Med J. 1995;108(12):895-7.

\section{Publisher's Note}

Springer Nature remains neutral with regard to jurisdictional claims in published maps and institutional affiliations.
Ready to submit your research? Choose BMC and benefit from:

- fast, convenient online submission

- thorough peer review by experienced researchers in your field

- rapid publication on acceptance

- support for research data, including large and complex data types

- gold Open Access which fosters wider collaboration and increased citations

- maximum visibility for your research: over $100 \mathrm{M}$ website views per year

At BMC, research is always in progress.

Learn more biomedcentral.com/submissions 